Article

\title{
Development and Validation of Miglitol and Its Impurities by RP-HPLC and Characterization Using Mass Spectrometry Techniques
}

\author{
Kesavan Balakumaran ${ }^{1,2, *}$, Mosesbabu Janagili ${ }^{1}$, Nagaraju Rajana ${ }^{1}$, Sureshbabu Papureddy ${ }^{1}$ \\ and Jayashree Anireddy ${ }^{2}$ \\ 1 Analytical Research, Custom Pharmaceutical Services, Dr. Reddy's Laboratories Ltd., Bollaram Road, \\ Miyapur, Hyderabad 500049, India; mosesbabuj@drreddys.com (M.J.); nagarajurajana@drreddys.com (N.R.); \\ psbabu8277@gmail.com (S.P.) \\ 2 Centre for Chemical Sciences \& Technology, Institute of Science and Technology, \\ Jawaharlal Nehru Technological University, Kukatpally, Hyderabad 500085, India; \\ jayashreeanireddy@gmail.com \\ * Correspondence: balakumarank@drreddys.com or kesavabalan@yahoo.co.in; Tel.: +91-9959098074 \\ Academic Editor: Thomas Erker \\ Received: 23 April 2016; Accepted: 11 August 2016; Published: 14 October 2016
}

\begin{abstract}
Alpha glucoside inhibitors used to treat type-2 diabetes mellitus (DM) are likely to be safe and effective. These agents are most effective for postprandial hyperglycemia. Miglitol is a type of drug used to treat type-2 DM. A simple, selective, linear, precise and accurate reversed-phase high-performance liquid chromatography (RP-HPLC) method was developed and validated for a related substance of miglitol and its identification, and characterization was done by different mass spectrometry techniques. The gradient method at a flow rate of $1.0 \mathrm{~mL} / \mathrm{min}$ was employed on a prevail carbohydrate ES column $(250 \times 4.6 \mathrm{~mm}, 5 \mu \mathrm{m}$ particle size $)$ at a temperature of $35^{\circ} \mathrm{C}$. Mobile phase A consisted of $10 \mathrm{mM}$ dipotassium hydrogen orthophosphate adjusted to $\mathrm{pH} 8.0 \mathrm{using}$ concentrated phosphoric acid and mobile phase B consisted of acetonitrile. The ultraviolet detection wavelength was $210 \mathrm{~nm}$ and $20 \mu \mathrm{L}$ of the sample were injected. The retention time for miglitol was about $24.0 \mathrm{~min}$. Forced degradation of the miglitol sample was conducted in accordance with the International Conference on Harmonisation ( $\mathrm{ICH}$ ) guidelines. Acidic, basic, neutral, and oxidative hydrolysis, thermal stress, and photolytic degradation were used to assess the stability-indicating the power of the method. Substantial degradation was observed during oxidative hydrolysis. No degradation was observed under the other stress conditions. The method was optimized using samples generated by forced degradation and sample solutions spiked with impurities and epimers. Good resolution of the analyte peak from peaks, corresponding to process-related impurities, epimers and degradation products, was achieved and the method was validated as per the ICH guidelines. The method can successfully be applied for routine analysis of miglitol.
\end{abstract}

Keywords: reverse phase liquid chromatography; miglitol; stability-indicating methods; forced degradation; high performance liquid chromatography; DNJ (1-deoxynojirimycin); mass spectrometry

\section{Introduction}

Diabetes mellitus (DM) is simply known as diabetes, a lifelong, progressive disease, which is a chronic metabolic disorder with steadily increasing prevalence all over the world. The relative deficiency of insulin secretion and varying degrees of insulin resistance is characterized by high circulating glucose levels [1]. As a result of this trend, it is quickly becoming an epidemic in poorly developed countries, with the number of people affected, expected to double in the next 
decade, due to an increase in the aging population, thereby adding burden to the existing health care providers [2]. No cure has been found yet for the disease; however, treatment modalities including lifestyle modification, treatment of obesity, oral hypoglycemic agents and insulin sensitizers that reduce insulin resistance are still recommended as first line treatment [3]. Recent research in pathophysiology of type $2 \mathrm{DM}$ led to the introduction of new medications like glucagon, peptide 1 analogues, dipeptidyl peptidase-IV inhibitors, glucagon-receptor antagonists and metabolic inhibitors of hepatic glucose output.

Miglitol ((2R,3R,4R,5S)-1-(2-hydroxyethyl)-2-(hydroxymethyl)piperidine-3,4,5-triol) is an oral anti-diabetic drug and an inhibitor of the intestinal $\alpha$-glucosidase. The inhibition of the glucosidase activity in the intestinal brush border blocks the breakdown of starch and disaccharides to absorbable monosaccharides, which results in a decrease in the intestinal absorption of starch, disaccharides and dextrin, leading to carbohydrate malabsorption and blunting of the postprandial rise in blood glucose. Miglitol was approved for use in the United States in 1999 and it was the second $\alpha$-glucosidase inhibitor (after acarbose) introduced into clinical practice. The current indications include the management of glycemic control in type 2 diabetes, used in combination with diet and exercise, with or without other oral hypoglycemic agents or insulin. Miglitol is available generically and under the brand name Glyset (Pfizer, New York, NY, USA) in tablets of 25, 50 and $100 \mathrm{mg}$. The typical initial dose in adults is $100 \mathrm{mg}$ with each meal (with the first bite) followed by a gradual increase. Miglitol causes malabsorption and gastrointestinal side effects are common including flatulence, diarrhea and abdominal boating.

Few analytical methods have been reported for the estimation of miglitol in bulk drug substance, tablets and the quantification of miglitol in biological samples. In order to follow the current good manufacturing practice of pharmaceuticals products, during the chemical synthesis of active ingredients, the possible impurities of reagents or starting materials have to be quantified to the lower limit based on the dosage of active ingredients [4-6]. The reported analytical method employs the quantification by ultra-performance liquid chromatography - electrospray ionisation mass spectrometry (UPLC-ESI-MS), high-performance liquid chromatography - ultra violet detector (HPLC-UV), capillary electrophoresis and high-performance liquid chromatography - evoprative light scattering detector (HPLC-ELSD) [5-10]. Some of the analytical methods reported for the determination of miglitol and its derivatives in the blood plasma have been previously described [11-17].

With the available information, no method has been reported for the determination of miglitol, 1-deoxynojirimycin (DNJ), its epimers, its potential impurities and its degradants in the drug substance using HPLC. The objective of this research work is to develop a simple stability-indicating liquid chromatographic method for the related substance. The forced degradation was performed as per International Conference on Harmonisation (ICH) recommended conditions, i.e., acid, base and water hydrolysis, oxidative, thermal and photolytic stressed conditions to prove the stability-indicating ability of the method. The mixture of the degraded sample and its related impurities were used to optimize the method. The method was also validated as per current regulatory bodies' requirements [18-23]. Mass spectrometry analysis was also performed using the liquid chromatography mass spectrometry (LCMS) compatible HPLC condition to determine the molecular weight of the impurities eluted by HPLC.

\section{Materials and Methods}

\subsection{Chemicals and Reagents}

Miglitol and its impurities were synthesized and purified using column liquid chromatography by the process research department of Custom Pharmaceutical Services of Dr. Reddy's laboratories limited, Hyderabad, India. Acetonitrile (HPLC-grade) and analytical reagent grade dipotassium hydrogen phosphate, sodium hydroxide, hydrochloric acid and hydrogen peroxide were purchased from Rankem (Mumbai, India) and used for the studies. Millipore Milli Q plus (Bangalore, India) purification system was used to prepare high pure water. 


\subsection{Equipment}

The method development attempts, forced degradation studies and the method validation were performed using Agilent 1100 series LC system with a diode array detector (Agilent Technologies, Santa Clara, CA, USA). The data were collected and processed using chemstation software (Agilent Technologies). The photolytic degradation was carried out using Binder KBS240 photolytic chamber (Bohemia, NY, United States), The peak homogeneity was established in Agilent LCMS 6410 QqQ instrument (Agilent Technologies).

\subsubsection{Mass Spectrometry}

The mass spectra of miglitol, epimeric impurities and DNJ were recorded with a LC-MS 6410 QqQ instrument (Agilent Technologies). For LC-MS identification of the impurities, the HPLC method given above was used by developing a LC-MS compatible method, applying $0.1 \%$ acetic acid as mobile phase A and acetonitrile as mobile phase B with gradients of 0/90, 35/70, 40/70, 50/90, 55/90 (time/\%B). The samples of the synthesized compounds were directly injected, using a syringe, at a concentration of (acetonitrile:water, 50:50, \%v/v). High resolution mass spectral data were recorded using Waters UPLC-TOF with LCT Premier XE Mass Lynx TM software (Milford, MA, USA). The conditions used were as follows: capillary voltage at $2300 \mathrm{~V}$, sample cone voltage $80 \mathrm{~V}$, dissolution temperature $250{ }^{\circ} \mathrm{C}$, source temperature $120^{\circ} \mathrm{C}$, desolvation gas flow $500 \mathrm{~L} / \mathrm{h}$ and cone gas flow $50 \mathrm{~L} / \mathrm{h}$.

\subsubsection{Chromatographic Conditions}

The chromatographic separation was optimized in the prevail carbohydrate ES column (W. R. Grace \& Co.-Conn., Columbia, MD, USA) with the dimension of $250 \mathrm{~mm} \times 4.6 \mathrm{~mm}$ and $3.5 \mu \mathrm{m}$ particle size. The elution involved $10 \mathrm{mM}$ dipotassium hydrogen orthophosphate in water and $\mathrm{pH}$ adjusted to 8.0 using concentrated phosphoric acid buffer as mobile phase $\mathrm{A}$ and acetonitrile as mobile phase B with gradient of 0/90, 35/70, 40/70, 50/90, 55/90 (Time/\%B). The flow rate of the mobile phase and the column temperature was set as $1.0 \mathrm{~mL} \cdot \mathrm{min}^{-1}$ and $35^{\circ} \mathrm{C}$. The detection wave length was optimized at $210 \mathrm{~nm}$. The column loading was finalized by injecting $20 \mu \mathrm{L}$ of miglitol $(10 \mathrm{mg} / \mathrm{mL})$ to the HPLC. A mixture of water and acetonitrile was used as a diluent in the same ratio.

\subsubsection{Preparation of Solutions}

Miglitol solution was prepared at a target analyte concentration (TAC) of $10,000 \mu \mathrm{g} \cdot \mathrm{mL}^{-1}$ in the diluent for related substances determination and assay determination. A stock solution with the blend of impurity A, B, C, D, E and F was also prepared in the same diluent for the preparation of the system suitability solution which contained $0.15 \%(w / w)$ of each impurity with respect to TAC of miglitol.

\subsubsection{Standard and Sample Preparation}

Preparation of standard stock solution-1

Weighed $50 \mathrm{mg}$ of miglitol and its impurities A, B, C, D, E and F in a $25 \mathrm{~mL}$ volumetric flask containing $15 \mathrm{~mL}$ of diluent (acetonitrile:water, 50:50, \%v/v), and made up to the mark with diluent.

Preparation of standard stock solution-2

Transferred $1.2 \mathrm{~mL}$ of standard stock solution-1 into a $25 \mathrm{~mL}$ volumetric flask containing $15 \mathrm{~mL}$ of diluent and made up to the mark with diluent.

Preparation of $0.15 \%(w / w)$ standard solution

Transferred $1.6 \mathrm{~mL}$ of standard stock solution- 2 into a $10 \mathrm{~mL}$ volumetric flask containing $3 \mathrm{~mL}$ of diluent and made up to the mark with diluent (with resepect to $10 \mathrm{mg} / \mathrm{mL}$ ). 
Preparation of $0.05 \%(w / w)$ standard solution (Limit of quantitation (LOQ) solution)

Transferred $3.3 \mathrm{~mL}$ of $0.15 \%(w / w)$ standard solution into a $10 \mathrm{~mL}$ volumetric flask containing $3 \mathrm{~mL}$ of diluent and made up to the mark with diluent (with respect to $10 \mathrm{mg} / \mathrm{mL}$ ).

Preparation of $0.02 \% w / w$ standard solution (Limit of detection (LOD) solution)

Transferred $3.3 \mathrm{~mL}$ of $0.05 \%(w / w)$ standard solution into a $10 \mathrm{~mL}$ volumetric flask containing $3 \mathrm{~mL}$ of diluent and made up to the mark with diluent (with respect to $10 \mathrm{mg} / \mathrm{mL}$ ).

Preparation of miglitol sample solution

Weighed $100 \mathrm{mg}$ of miglitol into a $10 \mathrm{~mL}$ volumetric flask containing $3 \mathrm{~mL}$ of diluent (acetonitrile:water, 50:50, \%v/v), and made up to the mark with diluent.

\subsection{Method Development}

The core objective of the chromatographic method is the detection and separation of all the known and degraded impurities of miglitol with a better baseline [16]. Deoxynijomycin is the intermediate precursor which is the potential impurity in the synthesis process of miglitol. Other epimeric impurities were possible in the process due to epimerization of DNJ. Other epimers of miglitol were synthesized by using the respective starting material. The final stage involved alkylation of DNJ using bromoethanol as alkylating agent. Due to the chromophore change, the $\lambda$ max. changed from $205 \mathrm{~nm}$ to $210 \mathrm{~nm}$ during this alkylation. At $205 \mathrm{~nm}$, there was low absorption signal response for the precursor and the related impurities. At $210 \mathrm{~nm}$, all the intermediates and related impurities had a good response and also miglitol had a reasonable response. Crude samples of miglitol and all related impurities were quantified against miglitol and found that the mass balance was close to $100 \%$, which is supporting the selection of $210 \mathrm{~nm}$.

Initial attempts for the method development were made in water and acetonitrile as mobile phases on a C18 reverse phase column, miglitol, DNJ and epimers of miglitol were eluted early at void volume.

Latter attempts for the method development were made using potassium hydrogen phosphate as mobile phase in an Acclaim mixed mode column (Thermo Fisher Scientific Inc., Waltham, MA, USA). Miglitol and DNJ were not separable from each other and with epimers is almost close retention. However, good peak shape and the resolution of all the related impurities was achieved using a prevail carbohydrate-ES column with the dimension of $250 \mathrm{~mm} \times 4.6 \mathrm{~mm}$ and $3.5 \mu \mathrm{m}$ particle size, by using solutions A and B as mobile phase. Though the selected stationary phase was not end-capped, there was no interaction between the analyte and the stationary phase. The selected stationary phase was very stable even at the highly basic $\mathrm{pH}$, present when ammonia was used as a mobile phase. Solution $\mathrm{A}$ contained dipotassium hydrogen orthophosphate at $\mathrm{pH} 8.0$ adjusted with orthophosphoric acid and solution B contained acetonitrile. The flow rate of the mobile phase was $1.0 \mathrm{~mL} \cdot \mathrm{min}^{-1}$. The gradient program was optimized to get the required retention of miglitol, $\mathrm{DNJ}$ and miglitol epimeric impurities. The HPLC gradient program was set as: time/\% solution B: 0/90, 35/70, 40/70, 50/90, and 55/90 with a gradient delay of $5 \mathrm{~min}$. The column temperature was set to $35^{\circ} \mathrm{C}$ in order to reduce the back pressure of the column with the optimized gradient program and the peak shape of DNJ, miglitol, and its epimeric impurities was improved. In the optimized conditions, it was observed that miglitol and its epimers (Impurity B, D and E), DNJ (Impurity F), monoalkylated miglitol (Impurity C) and dialkylated miglitol (Impurity A) were well separated with a resolution greater than 1.5 and no interference of blank (Figures 1 and 2). The system suitability resulted within the acceptance criteria (Table 1) and the developed LC method was found to be specific for miglitol, its known impurities and its degradation impurities. The structure of the miglitol active pharmaceutical ingredient and its impurities namely $\mathrm{A}$, $\mathrm{B}, \mathrm{C}, \mathrm{D}, \mathrm{E}, \mathrm{F}$ and miglitol $\mathrm{N}$-Oxide impurity are represented in Table 2. 


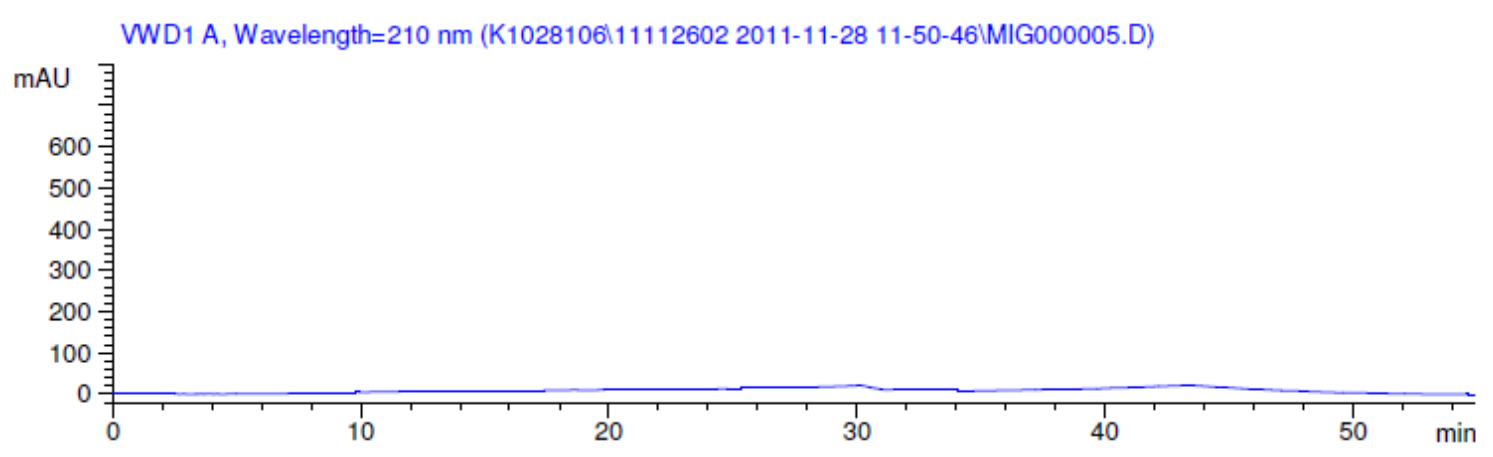

Figure 1. Blank chromatogram.

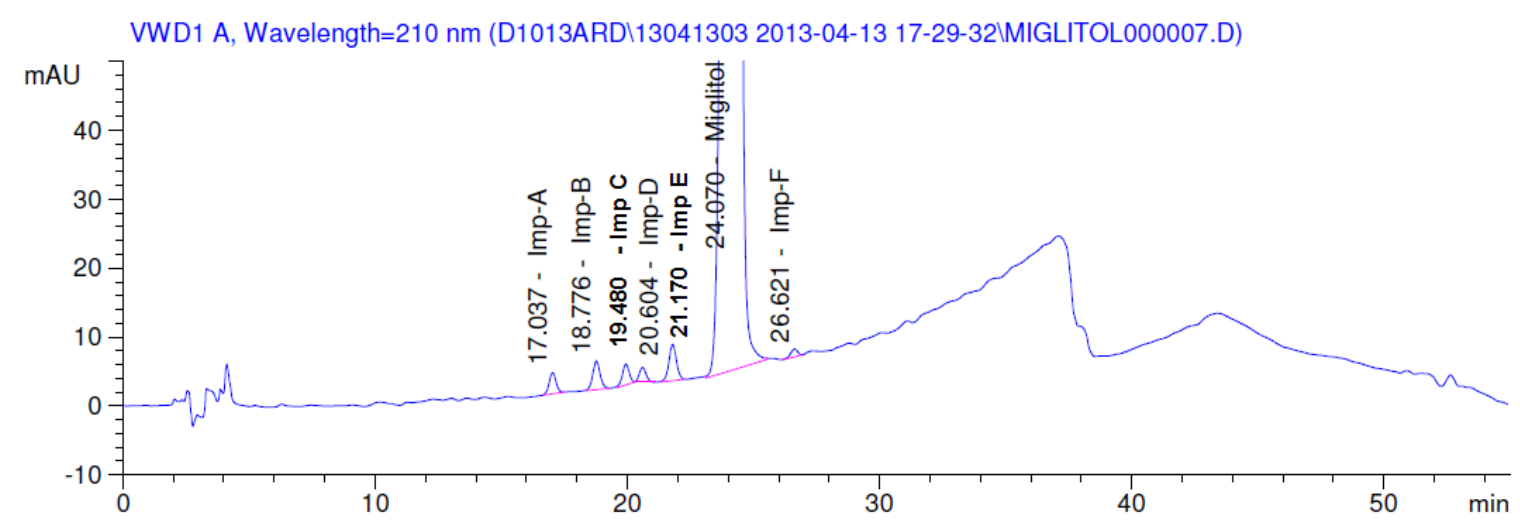

Figure 2. Typical system suitability test chromatogram.

Table 1. Limit of detection (LOD), limit of quantification (LOQ), regression and precision data.

\begin{tabular}{cccccccc}
\hline \multicolumn{1}{c}{ Parameter } & Miglitol & Imp A & Imp B & Imp C & Imp D & Imp E & Imp F \\
\hline $\begin{array}{l}\text { LOD \% }(w / w) \\
\text { w.r.t analyte concentration }\end{array}$ & 0.02 & 0.02 & 0.02 & 0.02 & 0.02 & 0.02 & 0.02 \\
\hline $\begin{array}{l}\text { LOQ \% }(w / w) \\
\text { w.r.t analyte concentration }\end{array}$ & 0.05 & 0.05 & 0.05 & 0.05 & 0.05 & 0.05 & 0.05 \\
\hline \multicolumn{1}{c}{ Slope } & 385.7 & 540.08 & 365.7 & 305.3 & 676.3 & 612.5 & 164.9 \\
\hline \multicolumn{1}{c}{ Intercept } & -0.271 & 0.833 & 0.875 & 0.121 & 0.124 & -2.669 & -1.22 \\
\hline Correlation coefficient & 0.999 & 0.999 & 1.000 & 0.998 & 0.999 & 0.999 & 0.999 \\
\hline Method precision (\% RSD) & 5.21 & 3.54 & 1.76 & 3.44 & 1.49 & 5.28 & 6.91 \\
\hline Intermediate precision (\% RSD) & 2.28 & 0.87 & 0.54 & 2.62 & 4.90 & 3.56 & 3.43 \\
\hline
\end{tabular}

W.r.t: with respect to RSD: relative standard deviation.

\subsubsection{Method Validation}

During method optimization, all chromatographic parameters were found to prove specificity, precision, linearity, accuracy, robustness and solution and mobile phase stability of active ingredients and its impurities. 
Table 2. Chemical name, structure and decoding list of miglitol and impurities.

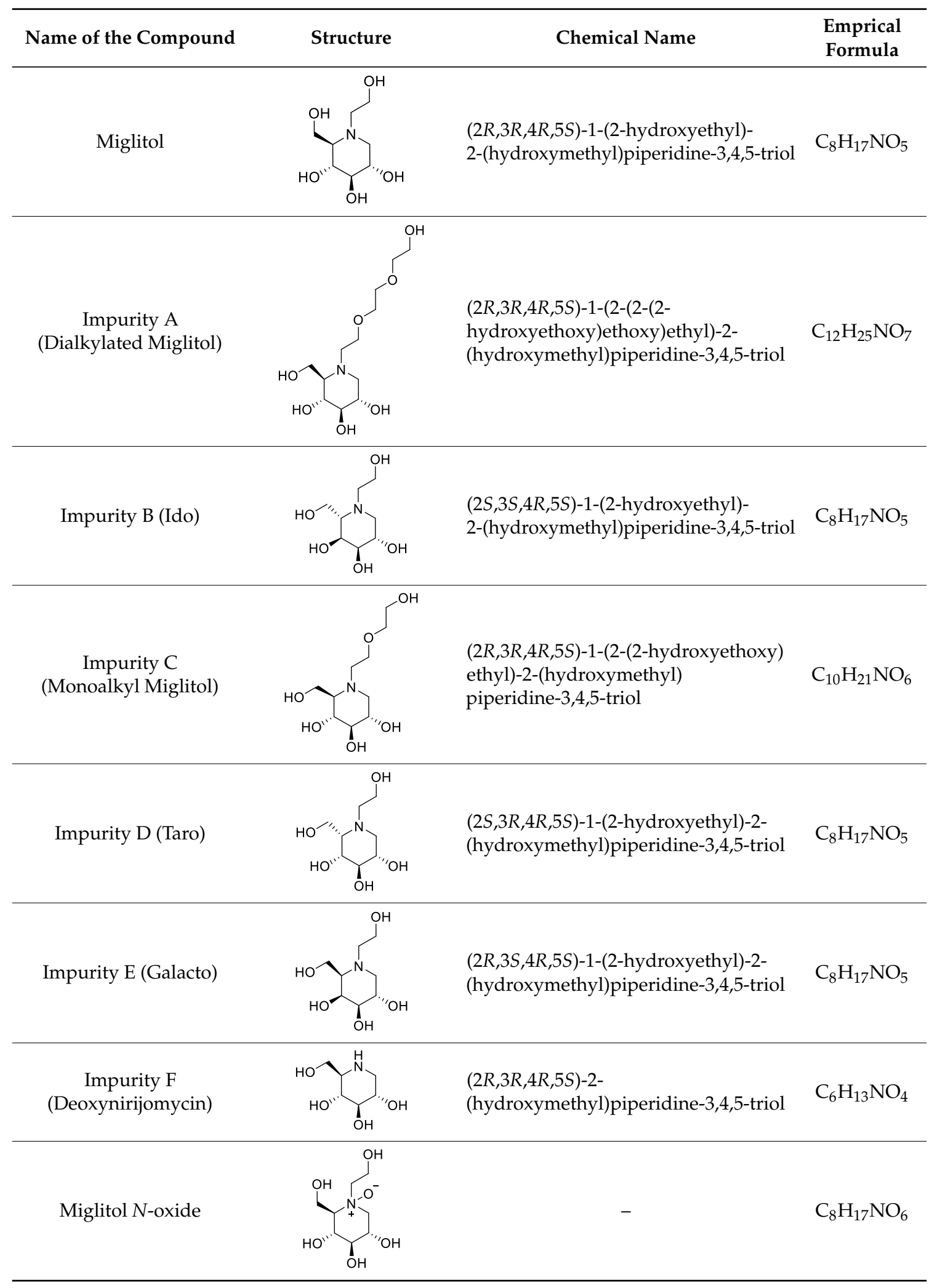

\subsubsection{Specificity}

Specificity is the ability of the method to measure the analyte in the presence of its potential impurities; they might be process related or degradation impurities. The specificity of the developed 
liquid chromatographic method for miglitol was established in the presence of its known impurities namely deoxynirjomycin (DNJ), miglitol empimers (imp-B, D, E and F), monalkyalted miglitol (imp-C) and di alkylated miglitol (imp-C) and miglitol degradation product. Forced degradation studies were performed on miglitol to grant the signal of the stability-indicating property and specificity of the developed method. The stress conditions engaged for degradation studies, as per the ICH recommended conditions, included photolytic, thermal, oxidation and hydrolysis in acid, base and water. The photolytic stressed studies were performed following ICH Q1B guidelines [19]. Samples were exposed for 11 days to 1.2 million lux hours for visible and $200 \mathrm{Wh} / \mathrm{m}^{2}$ for ultraviolet [19]. The thermal stress was done at $105^{\circ} \mathrm{C}$ for 10 days. The acid, base stress was performed with $0.5 \mathrm{~N} \mathrm{HCl}$ and $0.5 \mathrm{~N} \mathrm{NaOH}$ at the concentrated sample solutions for 10 days at room temperature $\left(25 \pm 2{ }^{\circ} \mathrm{C}\right)$ and further dilution of the analyte concentration was performed for the quantification of miglitol and its degradants. Water hydrolysis was performed for 10 days at room temperature. The oxidation stress was done for $1 \mathrm{~h}$ at room temperature [19]. Peak purity of stressed samples of miglitol and the spiked solutions of Impurity A, Impurity B, Impurity C and epimers were checked by Agilent 1100, diode array detector (DAD) (Agilent Technologies).

\subsubsection{Precision}

The precision of an analytical procedure expresses the closeness of agreement between a series of measurements from multiple sampling of the homogenous sample under prescribed conditions.

Six individual solution preparations were made with each of the known impurities at $0.15 \%(w / w)$ level. Quantification of individual impurities and miglitol was done for each of the preparations and the percentage of relative standard deviation RSD of the content of the impurities was determined. Method precision experimentation was repeated with different lots of column and different instrument in the same laboratory to evaluate the intermediate precision.

\subsubsection{Linearity}

The linearity of an analytical test procedure is its ability to obtain test results within the given range, which is directly proportional to the concentration of the analyte in the sample. The linearity of the method was established for miglitol and its impurity. The solution of miglitol and its known impurities was prepared at five different concentrations from $0.05 \%$ to $0.30 \%(w / w)$ of analyte concentration. The regression line was plotted with area versus concentration using the method of least-squares analysis. The values of the slope and $Y$-intercept of the plot were calculated.

\subsubsection{Accuracy}

Accuracy of impurities at each level was established by standard addition of the known quantities of impurities in test sample and calculating the recovery. The study was carried out in triplicate at LOQ, $0.075,0.15$ and $0.225 \%(w / w)$ of the TAC. The recovery of impurities was calculated by calculating the amount of impurities spiked and the amount of the impurity calculated from the spiked sample.

\subsubsection{Solution Stability and Mobile Phase Stability}

The solution stability was measured by keeping both test solutions and impurities at $0.15 \%$ specification level in tightly capped volumetric flasks at room temperature for $48 \mathrm{~h}$. The sample solutions were analysed at initial, $24 \mathrm{~h}, 48 \mathrm{~h}$. The stability of the mobile phase was also measured for $48 \mathrm{~h}$ by analysing the freshly prepared reference solutions at initial, $24 \mathrm{~h}$ and $48 \mathrm{~h}$. The mobile phase was kept constant during the study.

\subsubsection{Robustness}

The robustness of an analytical procedure is a measure of its capacity to remain unaffected by small, but deliberate variations in method parameters and provides an indication of its reliability 
during normal usage. The flow rate of the mobile phase was $1.0 \mathrm{~mL} / \mathrm{min}$. To study the effect of flow rate on the system precision, it was changed by 0.1 units to $0.9 \mathrm{~mL} / \mathrm{min}$ and $1.1 \mathrm{~mL} / \mathrm{min}$, while mobile phase components were held constant and the effect of flow rate was studied. The column temperature was studied by changing the $50{ }^{\circ} \mathrm{C}$ mentioned in the chromatographic conditions to $45{ }^{\circ} \mathrm{C}$ and $55^{\circ} \mathrm{C}$ and it was found that the results did not change.

\section{Results and Discussion}

\subsection{Mass Spectrometry Interpretation of Miglitol, 1-Dzeoxynojirimycin and Other Impurities}

Structural characterization of miglitol and all the other impurities was performed using various mass spectral data by determining the molecular ion and its fragmentation. Electrospray ionization and triple quadrupole mass spectrometry was used to determine the $\mathrm{m} / \mathrm{z}$ ratio of the molecular ions of all the structures using fragmentor voltage of 10 with a collision energy of $0 \mathrm{eV}$. The molecular ion $[\mathrm{M}+\mathrm{H}]^{+}$reported in Table 3 confirms the structure. In addition, fragmentation for each compound was studied using tandem mass spectrometry (MS/MS) by varying the collision energy and fragmentor voltage. High pure nitrogen gas was used as collision gas to get more accurate fragmentation data using electrospray ionization with fragmentor voltage at 135 and collision energy 20 eV (Figure 3). The MS/MS spectral data showed a similar finger print region for miglitol and its epimers. Due to the cyclic moiety, multiple fragments are observed in the spectral data. However, the retention time for all the compounds could be differentiated in the HPLC chromatogram showing the specificity of the LC method. However, for impurity A and impurity $C$ the extension of aliphatic chain was confirmed by getting base peak at 190.1 and additional peak at 234.1 with the same fragmentation voltage and collision energy. The fragmentation was also studied with high collision energy $50 \mathrm{eV}$, in which many smaller fragmentation peaks were observed making the interpretation of the fragmentation pattern more complex. Hence, initial energy $(20 \mathrm{eV})$ data is more appropriate rather than the later $(50 \mathrm{eV})$. In the case of miglitol N-oxide impurity, when molecular ion 224.1 was subjected to MS/MS, a strong base signal of 176.1 was observed. This might be due to fragmentation of the aliphatic chain in $\mathrm{C} 1$. The high resolution mass spectral data (Figure 4) of miglitol and all the other compounds was studied. The exact mass of the compound is reported in Table 4. The fact that it shows less than 5 ppm difference, confirms that the structure and double bond equivalence (DBE) derived from the high resolution mass spectrometry HRMS instrument also matches the structure.

Table 3. Liquid chromatography mass spectrometry (LCMS) and tandem mass spectrometry (MS/MS) data of miglitol and other compounds.

\begin{tabular}{cccc}
\hline & & \multicolumn{2}{c}{ LCMS-MS/MS } \\
\hline & {$[\mathbf{M}+\mathbf{H}]^{+}$} & Collision energy $(\mathbf{e V})$ & Fragmentation pattern $(\mathbf{m} / \mathbf{z})$ \\
\hline \multirow{2}{*}{ Miglitol } & \multirow{2}{*}{208.2} & 20 & $190.10,172.10,154.10,146.10,74.10$ \\
& & 50 & $140.10,96.10,80.10,56.20$ \\
\hline Imp-A & 296.2 & 20 & $146.10,128.10,110.10,102.10,69.20,60.20$ \\
\hline \multirow{2}{*}{ Imp-B } & \multirow{2}{*}{208.2} & 20 & $190.10,172.10,154.10,146.10,74.10$ \\
& 252.2 & 50 & $140.10,96.10,80.10,56.20$ \\
\hline Imp-C & 20 & $190.10,190.10,172.10,118.10,86.10,58.20$ \\
\hline \multirow{2}{*}{ Imp-D } & 208.2 & 20 & $140.10,94.10,80.10,56.20$ \\
\hline \multirow{2}{*}{ Imp-E } & \multirow{2}{*}{208.0} & 50 & $190.10,172.10,154.10,146.10,74.10$ \\
& 164.2 & 50 & $146.10,128.10,110.10,69.20,60.20$ \\
\hline Imp-F & 204.2 & 20 & $176.10,146.10,74.20$ \\
\hline MIG N-Oxide & 20 &
\end{tabular}



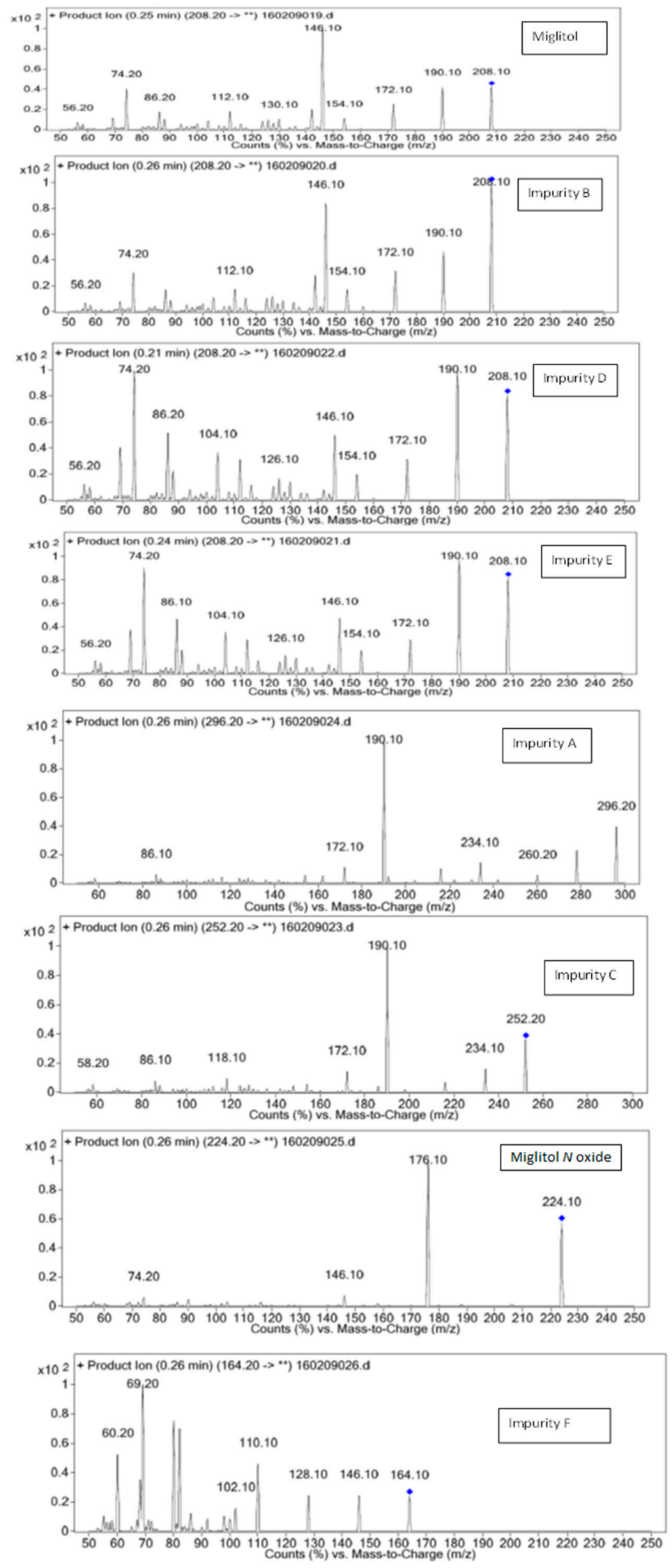

Figure 3. Fragmentation spectral data for miglitol and its impurities. 


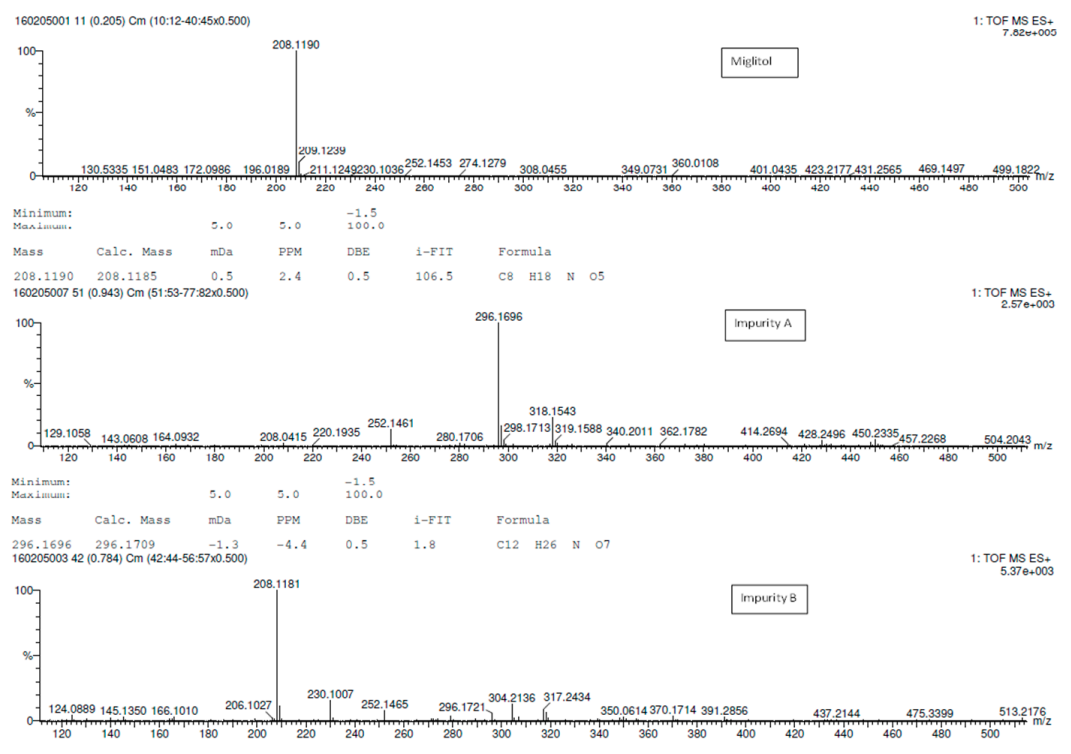

$\begin{array}{llll}\text { Minimum: } & & & -1.5 \\ \text { Maximum: } & 5.0 & 5.0 & 100\end{array}$

Mass Calc. Mass MDa PPM DBE i-FIT Formula

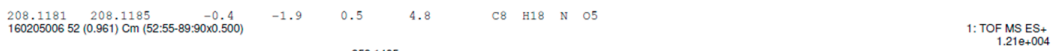

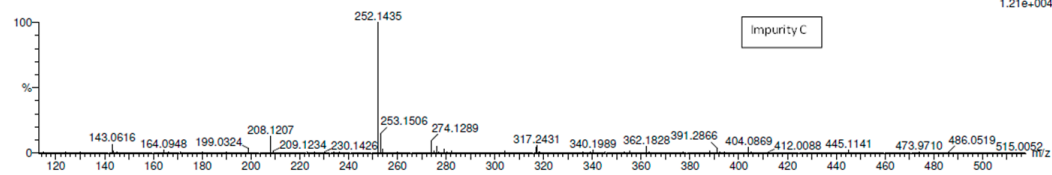

$\begin{array}{llll}\text { Minimum: } & & & -1.5 \\ \text { Maximum: } & 5.0 & 5.0 & 100.0\end{array}$

Mass Calc. Mass MDD PPM DBE i-FIT Formula

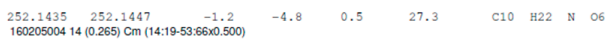

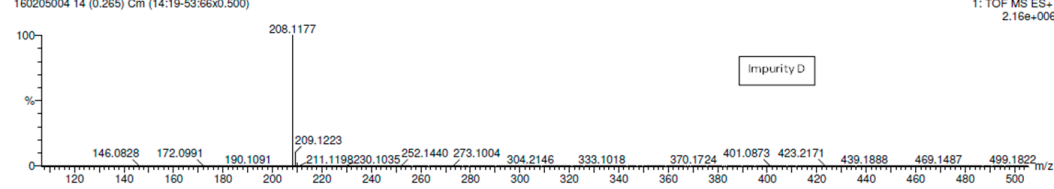

$\begin{array}{llll}\text { Minimum: } & & -1.5 \\ \text { Maximum: } & 5.0 & 5.0 & 100.0\end{array}$

Mass Calc. Mass MDa PPM DBE $\quad$ i-FIT Eormula

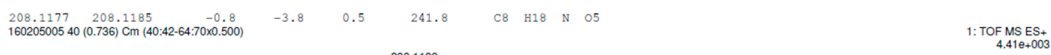

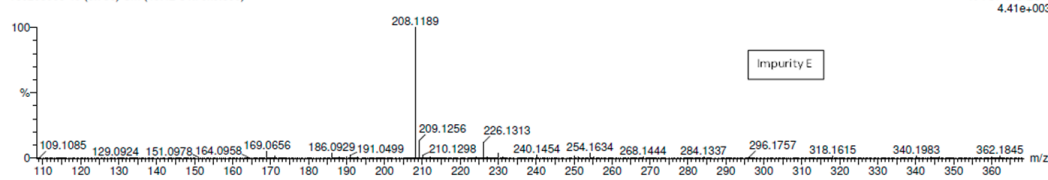

$\begin{array}{llll}\text { Minimum: } & & & \\ \text { Maximum: } & 5.0 & 5.0 & \begin{array}{l}-1.5 \\ 100.0\end{array}\end{array}$

Mass Calc. Mass MDa PPM DBE

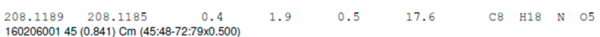

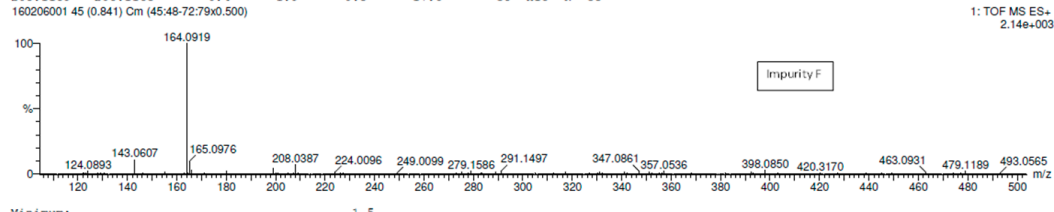

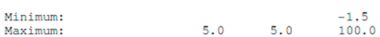

Mass Calc. Mass MDa PPM DBE i-FIT Formula

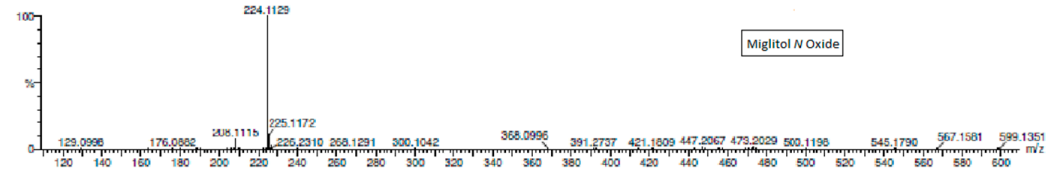

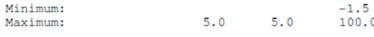

$\begin{array}{llllll}\text { Mass Calc. Mass } & \text { mDa } & \text { PPM } & \text { DBE } & \text { 1-FIT } & \text { Formula }\end{array}$

Figure 4. HRMS spectral data for miglitol and its impurities. 
Table 4. High resolution mass spectrometry (HRMS) data of miglitol (MIG) and other compounds.

\begin{tabular}{ccccc}
\hline \multirow{2}{*}{$\begin{array}{c}\text { Name of } \\
\text { Compound }\end{array}$} & {$[\mathbf{M}+\mathbf{H}]^{+}$} & ppm & $\begin{array}{c}\text { Houble Bond } \\
\text { Equivalance }\end{array}$ & $\begin{array}{c}\text { Elemental } \\
\text { Composition }\end{array}$ \\
\cline { 2 - 5 } & 208.1190 & 2.4 & 0.5 & $\mathrm{C}_{8} \mathrm{H}_{18} \mathrm{NO}_{5}$ \\
Miglitol & 296.1696 & -4.4 & 0.5 & $\mathrm{C}_{12} \mathrm{H}_{26} \mathrm{NO}_{7}$ \\
Imp-A & 208.1185 & -1.9 & 0.5 & $\mathrm{C}_{8} \mathrm{H}_{18} \mathrm{NO}_{5}$ \\
Imp-B & 252.1435 & -4.8 & 0.5 & $\mathrm{C}_{10} \mathrm{H}_{22} \mathrm{NO}_{6}$ \\
Imp-C & 208.1177 & -3.8 & 0.5 & $\mathrm{C}_{8} \mathrm{H}_{18} \mathrm{NO}_{5}$ \\
Imp-D & 208.1189 & 1.9 & 0.5 & $\mathrm{C}_{8} \mathrm{H}_{18} \mathrm{NO}_{5}$ \\
Imp-E & 164.0919 & -2.4 & 0.5 & $\mathrm{C}_{6} \mathrm{H}_{14} \mathrm{NO}_{4}$ \\
Imp-F & 224.1129 & -2.2 & 0.5 & $\mathrm{C}_{8} \mathrm{H}_{18} \mathrm{NO}_{6}$ \\
\hline MIG N-Oxide & & &
\end{tabular}

\subsection{Results of Forced Degradation Studies}

Degradation was not observed in stressed conditions when the analyte was subjected to photolytic, thermal, acid, base or water hydrolysis. The degradation of the drug was observed only under oxidative conditions. Miglitol under oxidative conditions leaded to the formation of one unknown degradation peak at the relative retention time (RRT) of 0.33 . The peak purity factor, over the threshold obtained in all stressed samples for the analyte peak, demonstrated its specificity (Figures 5-12). The summary of the forced degradation is captured in Table 5. The mass of the degradant is 16 units higher than the molecular weight of miglitol. Further studies can be done by characterizing this degradation impurity to understand the possible impurities during the stability and the metabolites of miglitol.

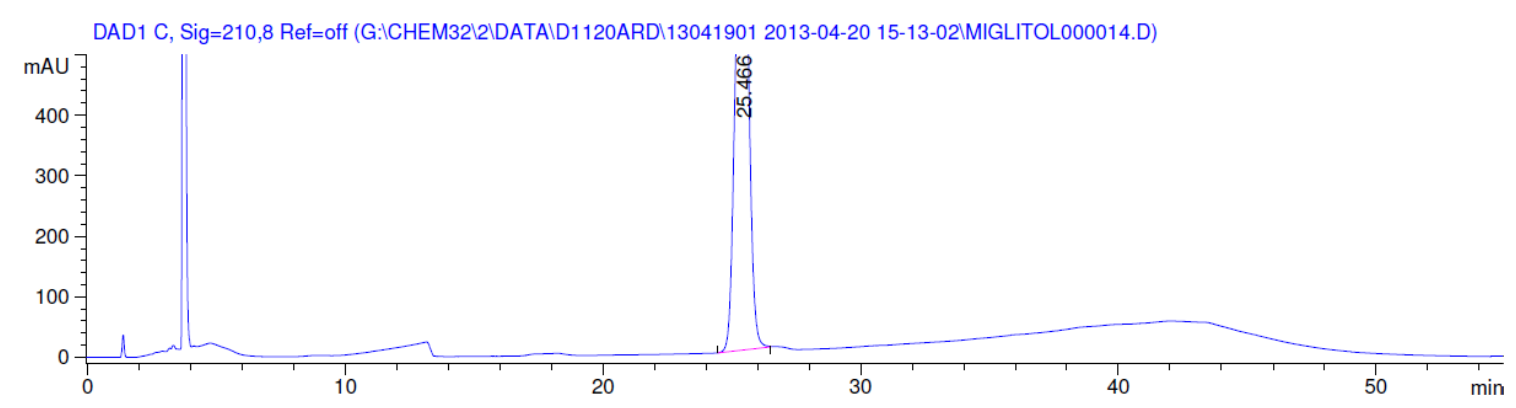

Figure 5. Chromatogram in base degradation.

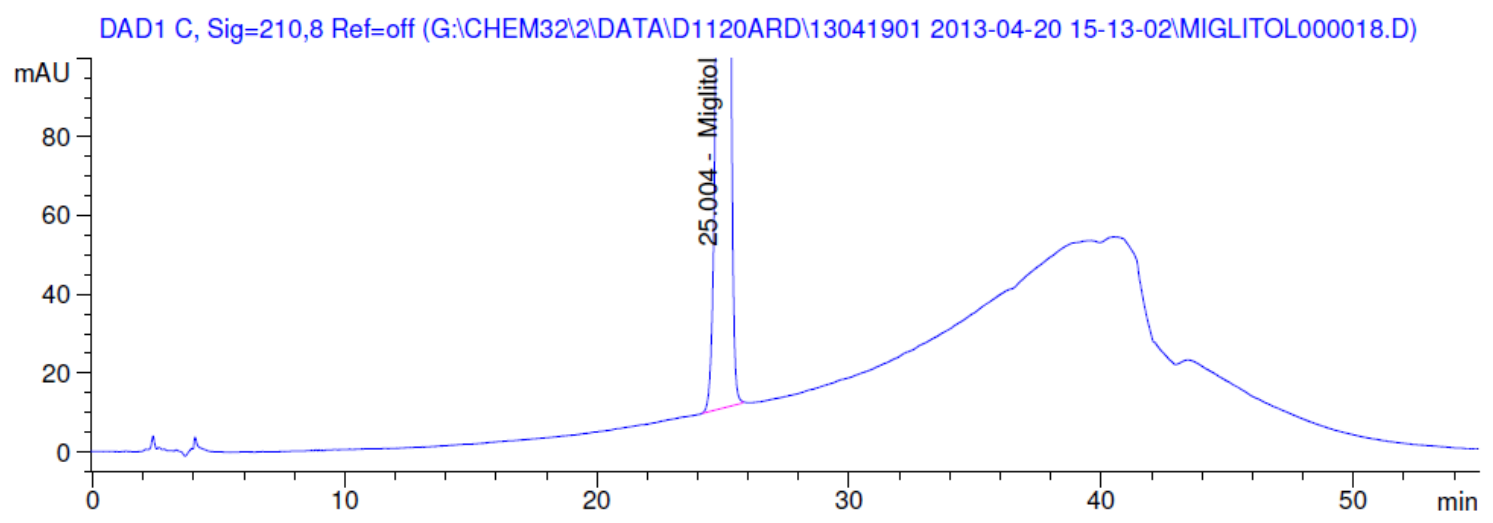

Figure 6. Chromatogram in thermal degradation. 
DAD1 C, Sig=210,8 Ref=off (G:ICHEM32\2\DATA\D1120ARD\13041901 2013-04-20 15-13-02\MIGLITOL000019.D)

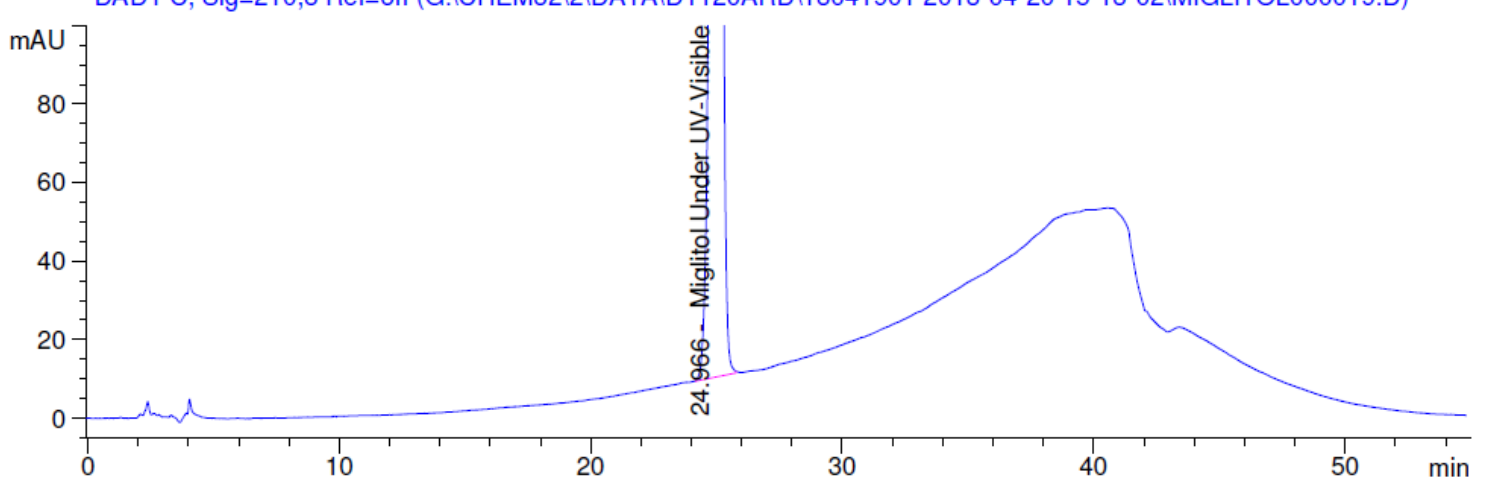

Figure 7. Chromatogram in ultraviolet (UV)-visible degradation.

DAD1 C, Sig=210,8 Ref=off (G:ICHEM32l2\DATAID1120ARD\13041901 2013-04-20 15-13-02\MIGLITOL000025.D)

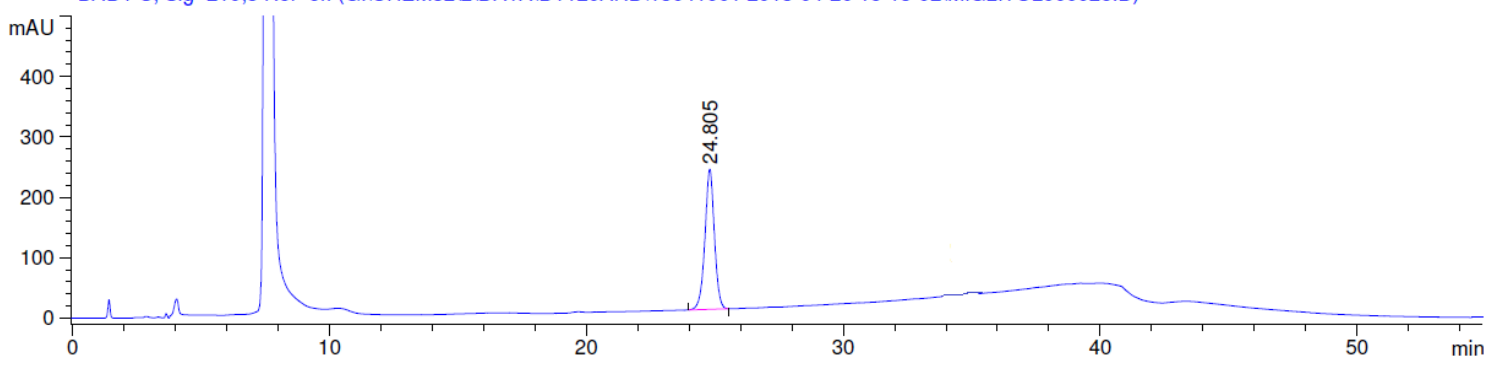

Figure 8. Chromatogram in oxidative degradation.

Data File G: \CHEM32\2\DATA\D1120ARD\13041901 2013-04-20 15-13-02\MIGLITOL000014.D Sample Name: Miglitol in $1 \mathrm{~N}$ NaOHSolution

Purity results peak 1 at $25.466 \mathrm{~min}$.

Signal DAD1 C, Sig-210,8 Ref-off (G: \CHEM32\2\DATA\D1120ARD 13041901 2013-04-20 15-13-02\MIGL
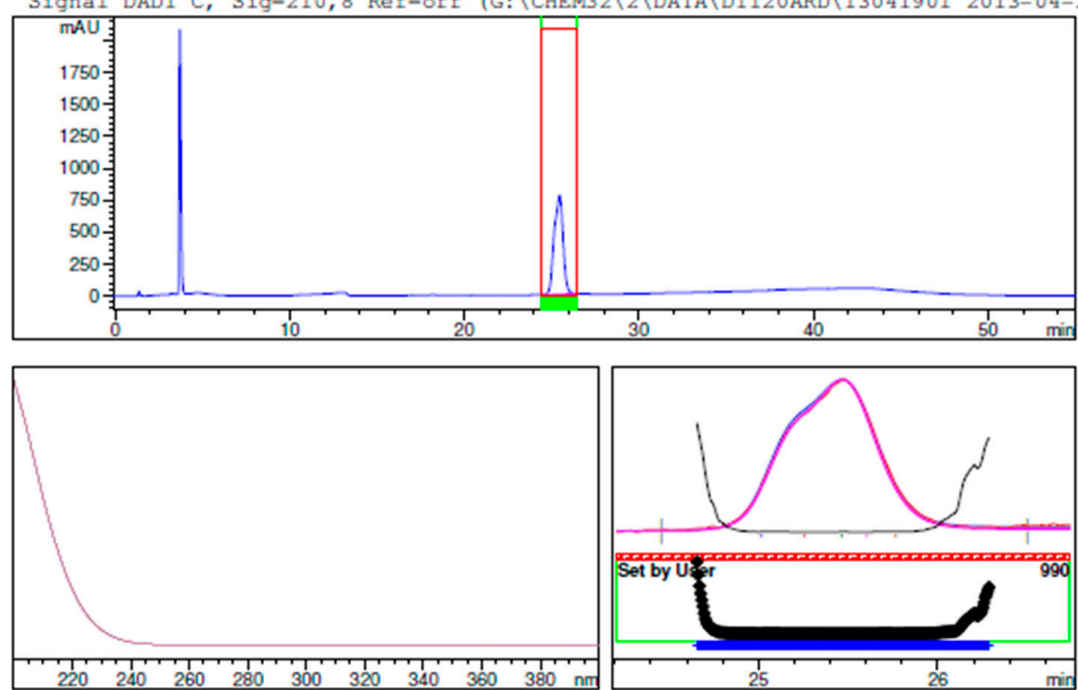

$\rightarrow$ The purity factor is within the threshold limit. <-

Purity factor : 999.465 (245 of 245 spectra are within the threshold limit.)

Threshold : 990.000 (Set by user)

Reference : Peak start and end spectra (integrated) (24.458/26.498)

Spectra : 5 (Selection automatic, 5)

Warning : Spectral absorbances $>1000 \mathrm{mAU}$ (see help for more information)

Figure 9. Peak purity in base degradation by diode array detector. 
Data File G: \CHEM32\2\DATA\D1120ARD 13041901 2013-04-20 15-13-02\MIGLITOL000025.D Sample Name: Miglitol in 3\% H2O2

Purity results peak 1 at $24.805 \mathrm{~min}$.
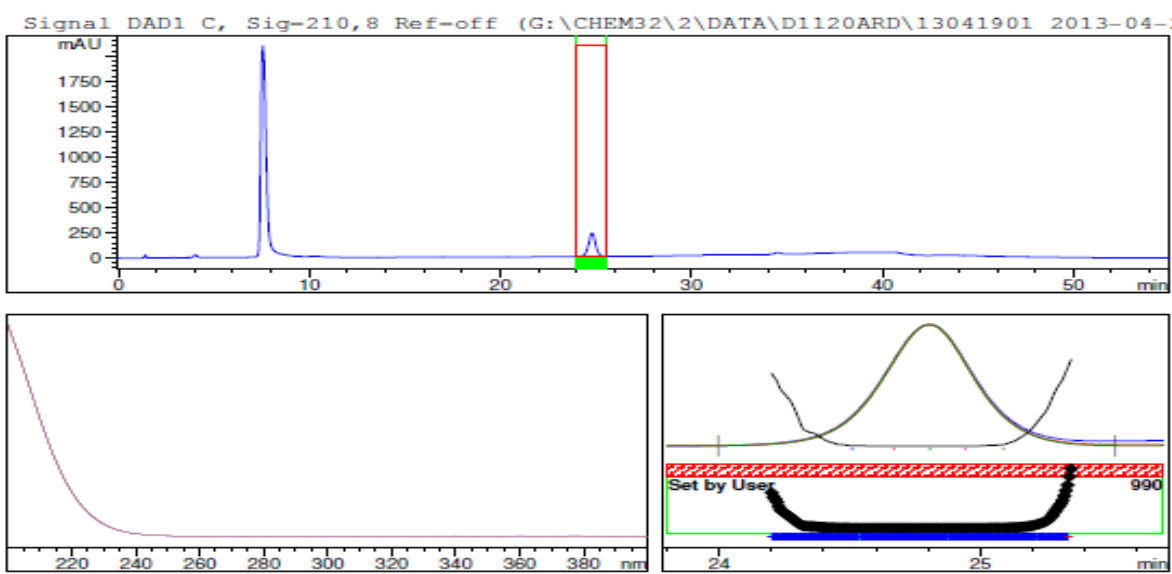

$\rightarrow$ The purity factor is within the threshold limit. <-

Purity factor : 999.277 (171 of 173 spectra are within the threshold 1imit.)

Threshold : 990.000 (Set by user)

Reference : Peak start and end spectra (integrated) (23.995/25.515)
Spectra

$\star * *$ End of Report $\star * *$

Figure 10. Peak purity in oxidative degradation by diode array detector.

Sample Name: Miglitol Under Thermal

Purity results peak 1 at $25.004 \mathrm{~min}$.

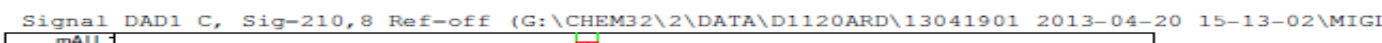
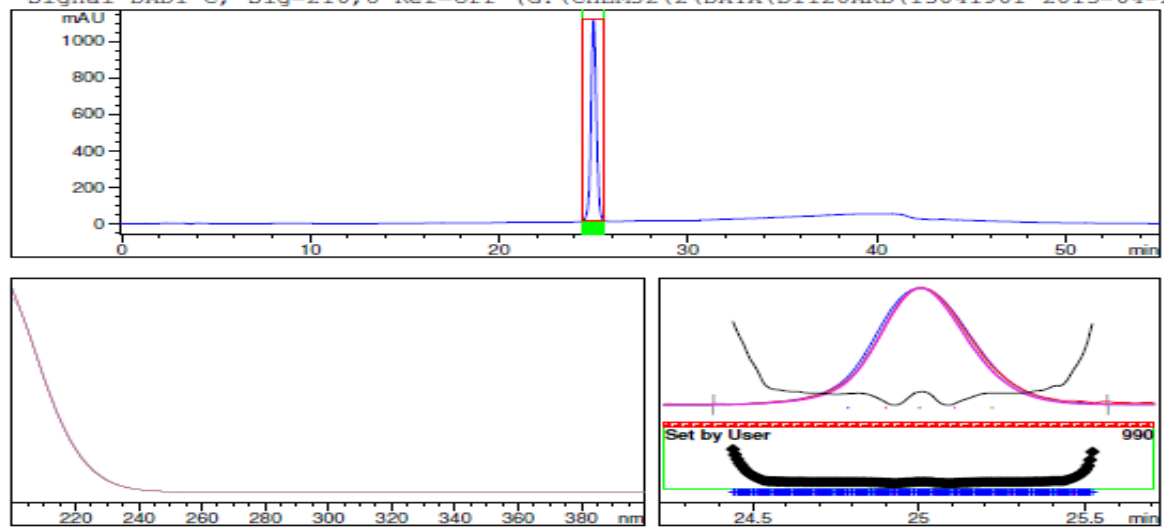

$\rightarrow$ The purity factor is within the threshold limito $<-$

purity factor : 999.459 (163 of 163 spectra are within the threshold limit.)

Threshold : 990.000 (Set by user)

Reference : Peak start and end spectra (integrated) (24.381/25.568)

Spectral absorbances > 1000 mAU (see help for more information)

$\star \star *$ End of Report ***

Figure 11. Peak purity in thermal degradation by diode array detector. 
Data File G: \CHEM32\2\DATA\D1120ARD\13041901 2013-04-20 15-13-02\MIGLITOL000019.D Sample Name: Miglitol Under UV-Visible

Purity results peak 1 at $24.966 \mathrm{~min}$.

Signa1 DAD1 C, Sig-210,8 Ref-off (G: \CHEM32\2\DATA \D1120ARD\13041901 2013-04-20 15-13-02\MIGL
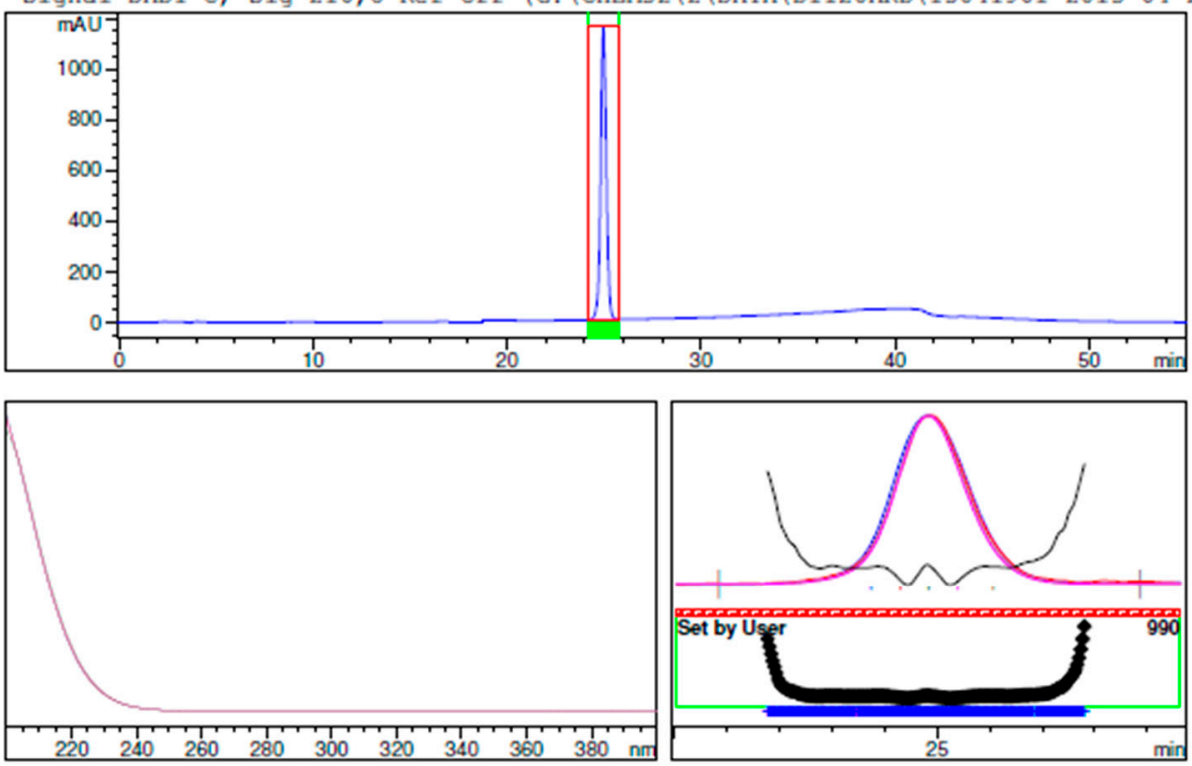

$\rightarrow$ The purity factor is within the threshold limit. <-

Purity factor : 999.238 (182 of 182 spectra are within the threshold limit.)

Threshold : 990.000 (Set by user)

Reference : Peak start and end spectra (integrated) (24.167/25.773)

Spectra : 5 (Selection automatic, 5)

Figure 12. Peak purity in UV-visible degradation by diode array detector.

Table 5. Summary of forced degradation results.

\begin{tabular}{ccccc}
\hline Stress Condition & Duration & $\begin{array}{c}\text { Purity of Miglitol after } \\
\text { Forced Degradation (\%) }\end{array}$ & $\begin{array}{c}\text { Content of Major } \\
\text { Degradant (\%) }\end{array}$ & Remarks \\
\hline Acid hydrolysis & 10 days & 100 & - & $\begin{array}{c}\text { No degradation } \\
\text { products formed }\end{array}$ \\
\hline Base hydrolysis & 10 days & 100 & 100 & $\begin{array}{c}\text { No degradation } \\
\text { products formed }\end{array}$ \\
\hline Oxidation & $1 \mathrm{~h}$ & 0.0 & - & $\begin{array}{c}\text { No degradationt degradation } \\
\text { product formed }\end{array}$ \\
\hline Thermal $\left(105{ }^{\circ} \mathrm{C}\right)$ & 10 days & 100 & - & $\begin{array}{c}\text { No degradation } \\
\text { products formed }\end{array}$ \\
\hline Photolytic as per ICH & 11 days & 100 & \\
\hline
\end{tabular}

\subsection{Precision}

All the individual values of impurity content and the assay in the precision and intermediate precision studies fell well in the range of confidence interval of average, confirming the excellent precision of the method. The recommended precision values in terms of percentage of relative standard deviation (RSD) should be not more than $15.0 \%$ for the related substance, whereas the percentage RSD of the content of impurities of miglitol in the method precision and the intermediate precision were within $5.2 \%$ and $2.28 \%$ respectively (Table 1 ). 


\subsection{Limit of Detection and Limit of Quantification}

The limit of detection of miglitol was $0.02 \%(w / w)$ (of TAC) for $20 \mu \mathrm{L}$ injection volumes. The limit of quantification for miglitol was $0.05 \%(w / w)$. Due to that, the response of all the impurities was quite good at $210 \mathrm{~nm}$, the concentration at LOD and the LOQ of the impurities was very much encouraging (Figure 13). This revealed the capability of the method for the quantification of impurities at lower level not only during the analysis of the sample at quality control but also to control them during the optimization of the process.

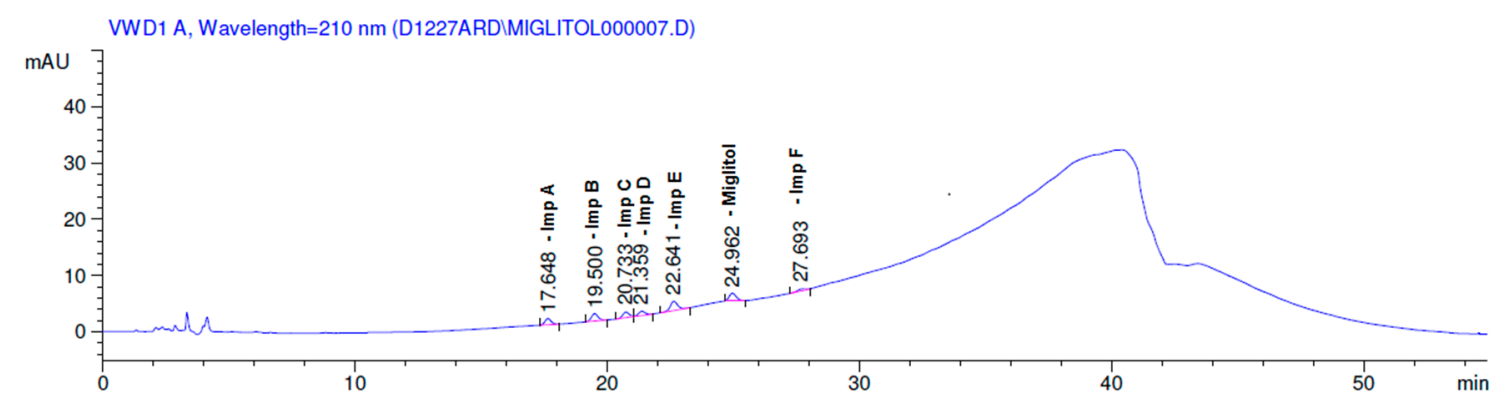

Figure 13. Limit of quantitation solution of miglitol and other impurities.

\subsection{Linearity}

Excellent correlation was achieved for the regression line of miglitol and its related impurities from $0.05 \%(w / w)$ to $0.30 \%(w / w)$. The correlation coefficient obtained for all the plots was greater than 0.997 . The $Y$-intercept of each plot was below $1.5 \%$ of the response at $0.15 \%(w / w)$ level of each impurity. Linear calibration plot for the assay was obtained over the calibration ranges tested, i.e., $0.05 \%$ $(w / w)$ to $0.30 \%(w / w)$. An excellent correlation exists between the peak area and concentration of miglitol by getting correlation coefficient greater than 0.999 . Y-Intercept for the assay concentration is also supportive that the plot is going almost through the origin.

\subsection{Accuracy}

The recovery of each impurity fell in the range from $87.6 \%$ to $103.1 \%$ and recovery data at individual impurity at each level captured in Table 6 . Individual assay value at each level in triplicate was close to the assay of miglitol reference standard evaluated. All the individual recovery value of the assay and impurities fell well within the confidence interval of mean values. Good recovery values reflected the exact values of RRF of impurities as well as the accuracy of the method.

\subsection{Solution Stability and Mobile Phase Stability}

The percentage RSD of area of all impurities during solution stability and mobile phase stability experiments were within $20 \%$. No significant changes were experienced in the content of any of the impurity during solution stability and mobile phase stability experiments. The solution stability and mobile phase stability experiment data confirmed that the sample solutions and mobile phases used were stable up to $48 \mathrm{~h}$. It is an advantage to have longer analysis time, which reduces the number of standard preparation in the quality control during regular analysis. 
Table 6. Results of accuracy for related substances.

\begin{tabular}{|c|c|c|c|c|}
\hline \multirow{2}{*}{ Compound } & \multirow{2}{*}{ Level } & \multirow{2}{*}{ Concentration $(\% w / w)$} & \multicolumn{2}{|c|}{ Recovery in \% } \\
\hline & & & Individual & Mean \\
\hline \multirow{4}{*}{ Imp-A } & LOQ & 0.05 & 99.2 & \multirow{4}{*}{95.65} \\
\hline & $50 \%$ & 0.075 & 96.3 & \\
\hline & $100 \%$ & 0.15 & 97.9 & \\
\hline & $150 \%$ & 0.225 & 89.2 & \\
\hline \multirow{4}{*}{ Imp-B } & LOQ & 0.05 & 100.2 & \multirow{4}{*}{96.03} \\
\hline & $50 \%$ & 0.075 & 97.6 & \\
\hline & $100 \%$ & 0.15 & 97.5 & \\
\hline & $150 \%$ & 0.225 & 88.8 & \\
\hline \multirow{4}{*}{ Imp-C } & LOQ & 0.05 & 101.3 & \multirow{4}{*}{99.95} \\
\hline & $50 \%$ & 0.075 & 101.7 & \\
\hline & $100 \%$ & 0.15 & 100.9 & \\
\hline & $150 \%$ & 0.225 & 95.9 & \\
\hline \multirow{4}{*}{ Imp-D } & LOQ & 0.05 & 93.0 & \multirow{4}{*}{97.58} \\
\hline & $50 \%$ & 0.075 & 99.1 & \\
\hline & $100 \%$ & 0.15 & 102.0 & \\
\hline & $150 \%$ & 0.225 & 96.2 & \\
\hline \multirow{4}{*}{ Imp-E } & LOQ & 0.05 & 94.0 & \multirow{4}{*}{96.63} \\
\hline & $50 \%$ & 0.075 & 94.5 & \\
\hline & $100 \%$ & 0.15 & 103.1 & \\
\hline & $150 \%$ & 0.225 & 94.9 & \\
\hline \multirow{4}{*}{ Imp-F } & LOQ & 0.05 & 91.0 & \multirow{4}{*}{95.25} \\
\hline & $50 \%$ & 0.075 & 99.3 & \\
\hline & $100 \%$ & 0.15 & 103.1 & \\
\hline & $150 \%$ & 0.225 & 87.6 & \\
\hline
\end{tabular}

\section{Conclusions}

Chromatographic and sample preparation conditions were developed and validated for miglitol and its isomeric impurities. The method was validated for miglitol and its epimeric impurities with appropriate accuracy, precision, linearity, robustness, solution stability and mobile phase stability. Identification and characterization were done by using mass spectrometry techniques. This method can be used for the routine analysis of the drug and it can also be applied for the formulated product.

It is prudent to remain optimistic in the diabetes research, which is growing within the basic, translational and development segments. Novel technology may eventually help to improve the outcome and quality of the drugs. Many treatment options for diabetes like lifestyle modulation, diet control, obesity and medication are currently available to aid in the control and management of this disease.

Note: DRL-IPDO communication No.: IPDO IPM-00500 has been allotted for this research article in the research laboratory.

Acknowledgments: The authors are thankful to the management of Reddy's Laboratories Ltd., Hyderabad, India, for providing the facilities to carry out this study. Cooperation from colleagues of Analytical Research \& Development and process research and development of Reddy's Laboratories Ltd. is acknowledged.

Author Contributions: J.A. and M.J. conceived and designed the experiments, B.K. performed the experiments and wrote the paper, N.R. and S.P. provided support for instrumentation and materials.

Conflicts of Interest: The authors declare no conflict of interest.

\section{References}

1. Aylward, G.W. Progressive changes in diabetics and their mangement. Eye (Lond.) 2005, 19, 1115-1118. [CrossRef] [PubMed]

2. Wild, S.; Roglic, G.; Green, A.; Sicree, R.; King, H. Global prevalance of diabetes; estimates for the year 2000 and projections for 2030. Diabetes Care 2004, 27, 1047-1053. [CrossRef] [PubMed] 
3. Aronson, D. hyperglycemia and pathobiology of diabetic complications. Adv Cardiol. 2008, 45, 1-16. [PubMed]

4. International Conference on Harmonization. Q3A (R2), Impurities in New Drug Substances; International Conference on Harmonization (ICH) Guidelines, 2006.

5. Nageswara Rao, R.; Nagaraju, V. An over view of the recent trends in development of HPLC methods for determination of impurities in drugs. J. Pharm. Biomed. Anal. 2003, 33, 335-377. [CrossRef]

6. Singh, S.; Handa, T.; Narayanam, M.; Sahu, A.; Junwal, M.; Shah, R.P. A critical review on the use of modern sophisticated hyphenated tools in the characterization of impurities and degradation products. J. Pharm. Biomed. Anal. 2012, 69, 148-173. [CrossRef] [PubMed]

7. Davis, S.N.; Granner, D.K. Insulin, Oral hypoglycemic agents and the pharmacology of endocrine Pancreas. In Goodman and Gilman's the Pharmacological Basis of Therapeutics, 10th ed.; Hardman, J.G., Limbird, L.E., Gilman, A.G., Eds.; MacGraw-Hill Companies Inc.: New York, NY, USA, 2001; pp. 1679-1714.

8. Asamoto, H.; Nobushi, Y.; Oi, T.; Uchikura, K. Determination of Miglitol by Column-Switching Ion-Pair HPLC with Tris(2,2'-bipyridine)ruthenium(II)-Electrogenerated Chemiluminescence Detection. Chem. Pharm. Bull. (Tokyo) 2015, 63, 476-480. [CrossRef] [PubMed]

9. Jain, R.; Lukram, O.; Dwivedi, A. Ultra-performance liquid chromatography electrospray ionization-tandem mass spectrometry method for the estimation of miglitol in human plasma using metformin as the internal standard. Drug Test. Anal. 2011, 3, 255-262. [CrossRef] [PubMed]

10. Cahours, X.; Daali, Y.; Cherkaoui, S.; Veuthey, J.L. Simultaneous analysis of polyhydroxylated alkaloids by capillary electrophoresis using borate complexation and evaluation of sweeping technique for sensitivity improvement. Chromatographia 2002, 55, 211-216. [CrossRef]

11. Ibrahim, F.A.; Ali, F.A. Kinetic determination of acarbose and miglitol in bulk and pharmaceutical formulations using alkaline potassium permanganate. Int. J. Biomed. Sci. 2007, 3, 20-30. [PubMed]

12. Li, X.; Wang, Y.; Wang, J.; Fawcett, J.P.; Zhao, L.; Gu, J. Determination of miglitol in human plasma by liquid chromatography/tandem mass spectrometry. Rapid Commun. Mass Spectrom. 2007, 21, 247-251. [CrossRef] [PubMed]

13. Nirogi, R.V.; Kandikere, V.N.; Shukla, M.; Mudigonda, K.; Maurya, S.; Boosi, R.K.; Yerramilli, A. Liquid chromatographic tandem mass spectrometry method for the quantification of miglitol in human plasma. Arzneimittelforschung 2006, 56, 328-336. [CrossRef] [PubMed]

14. Wang, F.; Jin, X.Z.; Xiu-mei, D. Determination of miglitol in human plasma by HPLC-MS/ESI. Chin. Pharm. J. 2005, 40, 51-53.

15. Chittora, N.C.; Shrivastava, A.; Jain, A. New RP-HPLC Method of Miglitol in Tablet Dosage form Including Forced Degradation Studies and Estimation in Spiked Rabbit Plasma. J. Young Pharm. 2009, 1, 364-370. [CrossRef]

16. Snyder, L.R.; Glajch, J.L.; Kirkland, J.J. Practical HPLC Method Development, 2nd ed.; Wiley Interscience: New York, NY, USA, 1997.

17. O'Neil, M.J. The Merck Index: An Encyclopedia of Chemicals, Drugs and Biologicals, 14th ed.; Merck Research Lab.: Whitehouse Station, NJ, USA, 2006; p. 1067.

18. International Conference on Harmonization. Q2 (R1), Validation of Analytical Procedures: Text and Methodology; ICH Guidelines, 2005.

19. International Conference on Harmonization. Q1B, Photostability Testing of New Drug Substances and Products; ICH Guidelines, 1996.

20. The United States Pharmacopoeia 39 and National Formulary 34, Asian ed.; United States Pharmacopoeia Convection: Rockville, MD, USA, 2016.

21. World Health Organization (WHO). Fact Sheet 275 [EB/OL]. 2003-09, 2016.

22. Health Ministry's Disease Control Division, Chinese Medical Association Diabetes Society. China Guideline for Diabetes; Peking University Press: Beijing, China, 2015.

23. Council of Europe. European Pharmacopoeia (Ph. Eur.), 8th ed.; Council of Europe: Strasbourg, France, 2015.

(C) 2016 by the authors; licensee MDPI, Basel, Switzerland. This article is an open access article distributed under the terms and conditions of the Creative Commons Attribution (CC-BY) license (http://creativecommons.org/licenses/by/4.0/). 